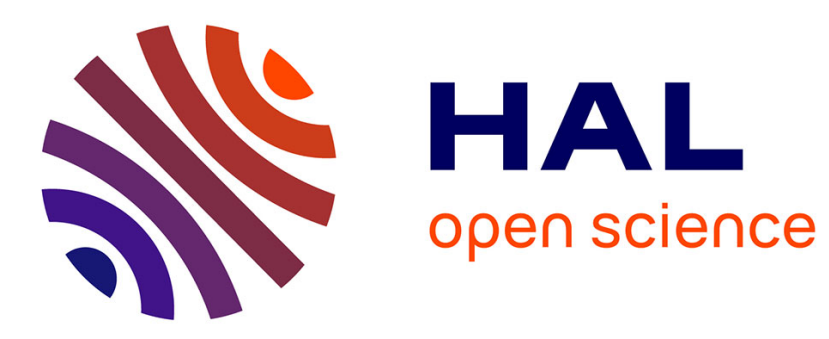

\title{
Carbon-Based Sorbent Coatings for the Determination of Pharmaceutical Compounds by Bar Adsorptive Microextraction
}

Samir Ahmad, Ana Mestre, Nuno Neng, Conchi Maria Concepcion Ovin Ania, Ana Carvalho, José Nogueira

\section{To cite this version:}

Samir Ahmad, Ana Mestre, Nuno Neng, Conchi Maria Concepcion Ovin Ania, Ana Carvalho, et al. Carbon-Based Sorbent Coatings for the Determination of Pharmaceutical Compounds by Bar Adsorptive Microextraction. ACS Applied Bio Materials, 2020, 3 (4), pp.2078-2091. 10.1021/acsabm.9b01206 . hal-02989843

\section{HAL Id: hal-02989843 https://hal.science/hal-02989843}

Submitted on 6 Nov 2020

HAL is a multi-disciplinary open access archive for the deposit and dissemination of scientific research documents, whether they are published or not. The documents may come from teaching and research institutions in France or abroad, or from public or private research centers.
L'archive ouverte pluridisciplinaire HAL, est destinée au dépôt et à la diffusion de documents scientifiques de niveau recherche, publiés ou non, émanant des établissements d'enseignement et de recherche français ou étrangers, des laboratoires publics ou privés. 


\section{Ahmad S, Mestre AS, Neng N, Ania CO, Carvalho AP, Nogueira}

J. Nanoporous hydrochars as sorbent coating for the determination of pharmaceutical compounds by bar adsorptive microextraction, ACS Appl. Bio Mater. 3 (2020) 2078-2091. https://doi.org/10.1021/acsabm.9b01206

\section{Carbon-based sorbent coatings for the determination of pharmaceutical compounds by bar adsorptive microextraction Samir M. Ahmad ${ }^{1}$, Ana S. Mestre ${ }^{1 *}$, Nuno R. Neng ${ }^{1}$, Conchi O. Ania ${ }^{2}$, Ana P. Carvalho $^{1}$, José M.F. Nogueira ${ }^{1^{*}}$}

${ }^{1}$ Centro de Química e Bioquímica and Centro de Química Estrutural, Faculdade de Ciências, Universidade de Lisboa, 1749-016 Lisboa, Portugal

${ }^{2}$ CNRS, CEMHTI UPR3079, University of Orléans, F-45071 Orléans, France

${ }^{*}$ Corresponding authors

E-mail address: asmestre@fc.ul.pt (Ana S. Mestre) and nogueira@fc.ul.pt (José M.F. Nogueira), Centro de Química e Bioquímica and Centro de Química Estrutural, Faculdade de Ciências, Universidade de Lisboa, Campo Grande Ed. C8, 1749-016, Lisboa, Portugal. Tel.: +351 217500899; Fax: +351 217500088.

Abstract

Thirteen carbon materials comprising commercial activated carbons and labmade materials (hydrochars and activated carbons) were assayed as enrichment phase in bar adsorptive microextration to monitor trace levels of ten common pharmaceutical compounds (PhCs) in environmental water matrices, 
25 including surface water, sea water, tap water and wastewater. Polar and non26 polar pharmaceuticals were selected - sulfamethoxazole, triclosan, 27 carbamazepine, diclofenac, mefenamic acid, 17a-ethinylestradiol, 17 $\beta$-estradiol, 28 estrone, gemfibrozil and clofibric acid - as model compounds to cover distinct

29 therapeutic classes. Despite having a less-developed porosity, data showed 30 that "in-house" prepared nanoporous hydrochars obtained from carbohydrates 31 at low temperature (e.g., $\left.180{ }^{\circ} \mathrm{C}\right)$ in the presence of an eutectic salt mixture 32 compete with the best commercial activated carbons for this particular 33 application. The combination of a micro and mesopore network with a rich 34 oxygen-based surface chemistry yielding an acidic nature allowed these 35 hydrochars to present the best overall recoveries (between 20.9 to $82.4 \%$ ) for 36 the simultaneous determination of the ten target PhCs with very distinct

37 chemical properties, by high performance liquid chromatography-diode array 38 detection (HPLC-DAD). 
41 Table to Contents (TOC)

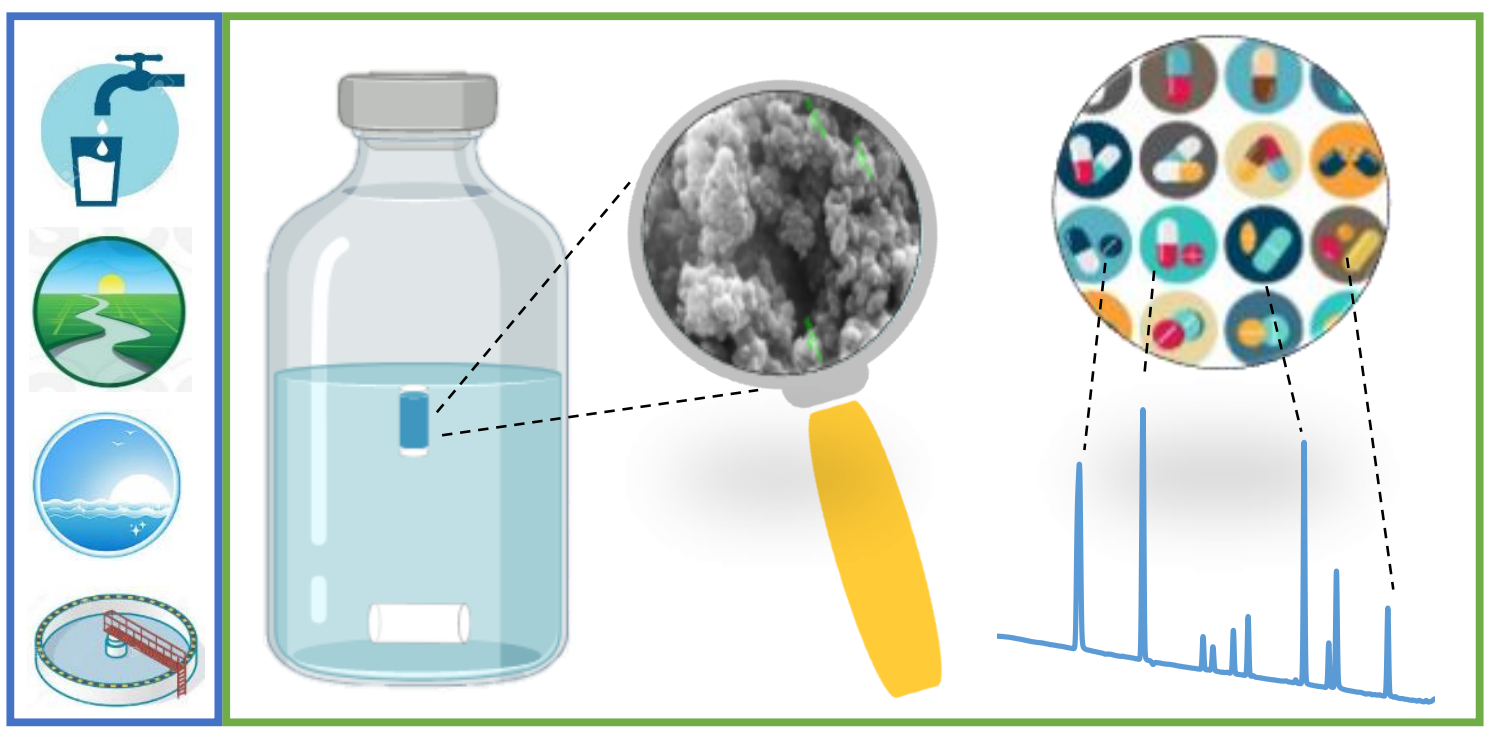

42

43 Keywords

44 Carbon hydrochars; Activated Carbons; Sorbent coating; Bar adsorptive

45 microextraction (BA $\mu \mathrm{E})$; HPLC-DAD; Pharmaceutical compounds;

46 Environmental water matrices. 
Pharmaceuticals and personal care products (PPCPs) encompass many different substances, such as drugs used in human and veterinary medicine,

50 fragrances, sunscreen agents, and cosmetics ingredients. More than 3000

51 PPCPs are currently marketed and new molecules enter the market yearly and 52 they are ubiquitously detected in treated wastewater [1]. Moreover, pharmaceuticals compounds (PhCs) are generally biologically active compounds that are often water soluble, therefore can be found in wastewaters and easily end up in natural waters, including ground water, river water, sea water and surface waters [2-5], usually at the trace level, ranging from $\mu \mathrm{L} \mathrm{L}^{-1}$ to $n g \mathrm{~L}^{-1}$ [6]. PhCs include multiple medicines classes, namely lipid regulators, antibacterials/antifungals, $\beta$-adrenergic blocking agents, analgesics, tranquilizers, hormones, and antiseptics, among many others [7]. The concern

60 for the possible ecotoxicological effects of these compounds is reflected on

61 decisions of the European Parliament in the field of water policy. In 2013, three

62 widely used PhCs, including the hormonal preparations 17a-ethinylestradiol and $6317 \beta$-estradiol, as well as the painkiller diclofenac, were listed in the watch list of 64 substances to be monitored in the European Union (EU) to support the 65 determination of appropriate measures to address the risk posed by them 66 (Directive 2013/39/EU) [8]. The first revision of this list in 2015 maintained these 67 three pharmaceuticals (Directive 2015/495/EU) [9] but in the most recent revision diclofenac, along with three other substances, was removed from the

69 watch list since the commission concluded that sufficient high-quality monitoring 70 data was already available (Directive 2018/840/EU) [10]. For these reasons, 71 there is a need for innovative analytical approaches that allow for their 
quantification in environmental water matrices. Furthermore, considering the EU

73 decision on water policy, the development of a simple methodology that allows

74 the simultaneous analysis of the most representative emerging $\mathrm{PhCs}$ in water matrices continues to be a hot research topic. As water bodies contain trace amounts of a large range of PhCs with distinct physicochemical properties, the challenge relies on the development of quantification techniques comprising both polar and non-polar compounds.

Many analytical approaches have been proposed to analyze trace levels of PhCs in environmental water matrices; these always include a sample enrichment step prior to gas or liquid chromatography [1,8-10]. In the last decades, the development of miniaturized passive sorption-based techniques for sample enrichment has increased, covering e.g., solid phase microextraction (SPME), stir bar sorptive extraction (SBSE) [14-16], and bar adsorptive microextraction $(\mathrm{BA} \mu \mathrm{E})$ as most representative for trace analysis of polar to nonpolar analytes in aqueous media [11-13]. BA $\mathrm{BE}$ is based on the floating sampling technology enrichment process, allowing for the possibility of selecting the most convenient sorbent coating upon the target PhCs involved $[11,18,19]$. In this regard, and recognizing the relevance of activated carbons as adsorbents of micropollutants, it is interesting to evaluate the potential of

91 different types of carbon materials -e.g., carbohydrate-derived hydrochars and 92 their activated counterparts-, as coating phases for a selective extraction of a 93 wide range of PhCs. Hydrochars can be obtained by the hydrothermal carbonization of a carbohydrate precursor under mild synthesis conditions using water as solvent. As opposed to activated carbons prepared from conventional activation routes, hydrochars are essentially non-porous solids characterized by 
97 displaying a surface chemistry rich in oxygen groups. The addition of eutectic

98 salt mixtures during the hydrothermal carbonization allows to obtain nanoporous

99 hydrochars with hierarchical porosity [20] and a rich amphoteric surface

100 chemistry. The combination of these features will prove to play a crucial role in

101 their high performance toward the quantification of $\mathrm{PhCs}$ with distinct

102 physicochemical properties.

103 This work aims to evaluate the performance of BA $\mu \mathrm{E}$ devices coated with

104 various carbon materials to simultaneously monitor traces of pharmaceutical

105 compounds (i.e. sulfamethoxazole, triclosan, carbamazepine, diclofenac,

106 mefenamic acid, 17a-ethinylestradiol, 17 $\beta$-estradiol, estrone, gemfibrozil and

107 clofibric acid) in deionized water and in environmental water matrices. The

$108 \mathrm{BA} \mu \mathrm{E}$ was used as the first step in the quantification and identification of the

109 PhCs, followed by microliquid desorption ( $\mu L D)$ and then high performance

110 liquid chromatography with diode array detection (HPLC-DAD). The

111 performance of the distinct carbon materials covering activated carbons,

112 nanoporous carbohydrate-based hydrochars and superactivated hydrochars

113 has been discussed in the light of their porous and chemical features. The

114 validation and application of the optimized methodology (including the influence

115 of polarity, back-extraction time and solvent, stirring rate) for real water matrices

116 is fully discussed, as well as the comparison with other microextraction-based

117 techniques.

118 2. Experimental

$119 \quad 2.1$ Reagents

120 Glucose, G (> $99 \%$ ), fructose, F (> $99 \%$ ) and sucrose, S (> $99 \%$ ) were

121 obtained from AnalaR NORMAPUR (Leuven, Belgium). Lithium chloride (LiCl, 
$12299 \%$ ) was acquired from Merck (Darmstadt, Germany), and zinc chloride ( $\mathrm{ZnCl}$,

$12398 \%)$ was acquired from Acros Organics (Geel, Belgium). Carbamazepine

124 (99.0 \%), triclosan (97.0\%), diclofenac sodium salt (98.0\%) 17- $\beta$-estradiol

125 (98.0\%), estrone (99.0\%), gemfibrozil (98.5\%), mefenamic acid (98.5\%),

126 clofibric acid $(98.0 \%)$, sulfamethoxazole $(98.0 \%)$ and potassium carbonate

$127\left(\mathrm{~K}_{2} \mathrm{CO}_{3}, 99 \%\right)$ were purchased from Sigma-Aldrich (Steinheim, Germany). 17-

128 a-ethinylestradiol (98.0 \%) was purchased from Riedel-de-Haën (Seelze,

129 Germany). Figure 1 depicts the chemical structures, as well as the $\mathrm{p} K_{\mathrm{a}}$ and log

$130 K_{\mathrm{O}}$ w values of the PhCs studied. The solvents used were HPLC-grade

131 methanol ( $\mathrm{MeOH}, 99.8 \%)$, and acetonitrile (ACN, $99.8 \%)$, obtained from Carlo

132 Erba (Arese, Italy). Sodium chloride ( $\mathrm{NaCl}, 99.5 \%)$ was purchased from Merck

133 Millipore (Darmstadt, Germany). Sodium hydroxide $(\mathrm{NaOH}, 98.0 \%)$ pellets

134 were obtained from AnalaR (BDH chemicals, Lutterworth, U.K.). Hydrochloric

135 acid $(\mathrm{HCl}, 37 \%)$, acetic acid $(99.5 \%)$ and potassium hydroxide $(\mathrm{KOH}, 85 \%)$

136 were purchased from Panreac (Barcelona, Spain). The acrylic acid (AA, $\geq 99 \%$ )

137 was purchased from Merck (Hohenbrunn, Germany). All chemicals were used

138 without further purification. Ultra-pure water was obtained from the Milli-Q water

139 purification systems (Merck Millipore, Darmstadt, Germany). 
<smiles>Cc1cc(NS(=O)(=O)c2ccc(N)cc2)no1</smiles>

Sulfamethoxazole pKa $: 1.97 ; 6.16$ $\log K_{\mathrm{O} / \mathrm{w}}: 0.79$<smiles>NC(=O)N1c2ccccc2C=Cc2ccccc21</smiles>

Carbamazepine p $K_{\mathrm{a}}: 15.96$

Log $K_{\mathrm{O} / \mathrm{w}}: 2.77$

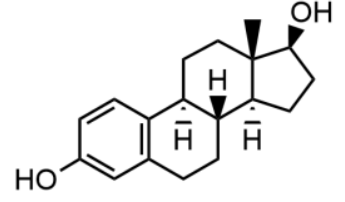

17- $\beta$-Estradiol pK $K_{\mathrm{a}}: 10.33$

Log $K_{\mathrm{O} / \mathrm{w}}: 3.75$<smiles>CC(C)(Oc1ccc(Cl)cc1)C(=O)O</smiles>

$\mathrm{p} K_{\mathrm{a}}: 3.37$

$\log K_{\mathrm{O} / \mathrm{W}}: 2.90$

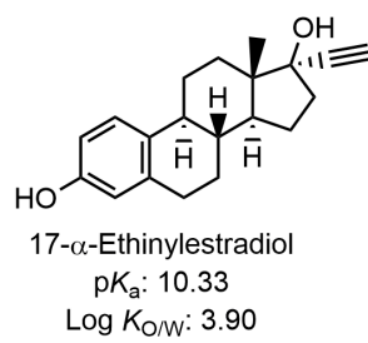

$\mathrm{H}_{\mathrm{O}}^{\mathrm{OH}}$

Gemfibrozil $\mathrm{pK}$ a: 4.42

Log $K_{\mathrm{O} / \mathrm{w}}: 4.39$

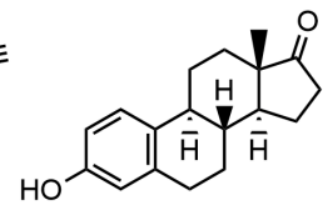

Estrone p $K_{\mathrm{a}}: 10.33$

Log $K_{\mathrm{O} / \mathrm{w}}: 4.31$

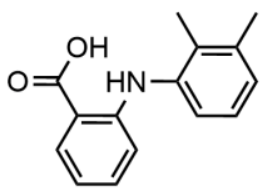

Mefenamic acid $\mathrm{pK}_{\mathrm{a}}: 3.89$

Log $K_{\mathrm{O} / \mathrm{W}}: 5.40$

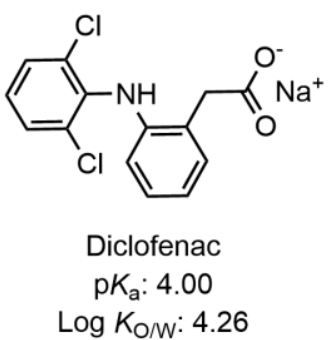<smiles>Oc1cc(Cl)ccc1Oc1ccc(Cl)cc1Cl</smiles>

Triclosan $\mathrm{pK}$ a: 7.68

Log $K_{\mathrm{O} / \mathrm{w}}: 4.98$

Figure 1 - Chemical structures, $\mathrm{p} K_{\mathrm{a}}$ and $\log K_{\mathrm{O} / \mathrm{w}}$ values of the analysed PhCs [21].

The hydrochars were prepared by hydrothermal carbonization of carbohydrates: $15 \mathrm{~cm}^{3}$ of $1.5 \mathrm{~mol} \mathrm{~L}^{-1}$ glucose or sucrose solutions introduced in

145 an autoclave and heated at $190^{\circ} \mathrm{C}$ during $5 \mathrm{~h}[22,23]$. These samples are

146 labeled as HG or HS according with the carbohydrate precursor (glucose and

147 sucrose, respectively). Modified sucrose-derived hydrochars were prepared by

148 a similar protocol but adding acrylic acid (e.g., 7, 14 or 27 wt.\%) to the starting 149 sucrose aqueous solution [24,25]. The modified hydrochars were labeled as

150 HSAAx, where $x$ stands for the amount of acrylic acid. The sucrose-derived

151 hydrochar was chemically activated as indicated elsewhere [22,23]. Briefly,

152 superactivated carbons $\mathrm{HS} / \mathrm{H} 800$ and $\mathrm{HS} / \mathrm{C} 800$ were prepared by activation of

$1531 \mathrm{~g}$ of sucrose-derived hydrochar (HS) with $4 \mathrm{~g}$ of, respectively, $\mathrm{KOH}$ and $154 \mathrm{~K}_{2} \mathrm{CO}_{3}$ during $1 \mathrm{~h}$ at $800{ }^{\circ} \mathrm{C}$. 
155 The synthesis of nanoporous hydrochars was inspired on the studies 156 reported by Fechler et al. for glucose [20]. Briefly, $11.25 \mathrm{~g}$ of eutectic $\mathrm{LiCl} / \mathrm{ZnCl}_{2}$ 157 salt mixture (23 molar \% $\mathrm{LiCl}$ and the remaining corresponds to $\mathrm{ZnCl}_{2}$ ) were 158 ground and homogenized in an agate mortar; then $4.5 \mathrm{~g}$ of a carbohydrate 159 precursor ( $G$ - glucose, $F$ - fructose or $S$ - sucrose) were added, and the 160 resulting mixture was grounded until obtaining a homogeneous sample. The 161 mixture carbohydrate:eutectic salt was introduced in a Teflon-line stainless steel 162 autoclave $\left(35 \mathrm{~cm}^{3}\right)$. After adding $2.3 \mathrm{~cm}^{3}$ of ultra-pure water, the autoclave was 163 closed, shaken vigorously, and placed in an oven (Medline Scientific Limited, 164 model $\mathrm{ON}-02 \mathrm{G})$ pre-heated to $180^{\circ} \mathrm{C}$. The hydrothermal treatment was 165 performed during $17 \mathrm{~h}$, after what the autoclave was cooled down to room 166 temperature, and the porous hydrochar was washed with distilled water up to no 167 detection of chlorine anions (i.e. no precipitation when $\mathrm{AgCl}$ is added). After 168 washing, the samples were dried at atmospheric pressure, ground and sieve to 169 store particles with dimensions $<0.297 \mathrm{~mm}$. The porous hydrochars were 170 labelled as npHy, where y stands for the carbohydrate precursor (G, $F$, or S: 171 npHG, npHF and npHS, respectively).

172 An activated carbon prepared by steam activation of expanded corkboard 173 granules at semi-industrial scale following the procedure reported in ref. [26] 174 was also used (Cork/S800). Commercial powdered activated carbon (PAC) 175 materials CN1 from Cabot-Norit (Com/CN1, supplied by Salmon \& Cia. (Lisbon, 176 Portugal)) and R from Riedel-de-Haën (Com/R, Seelze, Germany) were tested 177 for comparison purposes. Further details on the synthesis and characterization 178 of some of these carbons were previously reported (see cited references), and it 179 is presented on table 1 for comparison purposes. 
181 Table 1 - Summary of the main textural and surface properties of the carbon materials used as

182 coatings (apparent surface area $-A_{\mathrm{BET}}$, micropore volume $-V_{\text {micro }}$ (pores with widths $<2 \mathrm{~nm}$ ),

183 mesopore volume $-V_{\text {meso }}$ (pores with widths between 2 and $50 \mathrm{~nm}$ ), pH at the point of zero

184 charge $\left.-\mathrm{pH}_{\mathrm{PZC}}\right)$.

\begin{tabular}{|c|c|c|c|}
\hline Type & Carbon material & Textural properties & Surface properties \\
\hline \multirow{4}{*}{$\begin{array}{l}\text { Activated } \\
\text { carbons }\end{array}$} & \multirow{3}{*}{$\begin{array}{l}\text { Commercial } \\
\text { (Com/CN1 and } \\
\text { Com/R) }\end{array}$} & $A_{\mathrm{BET}} \approx 1000 \mathrm{~m}^{2} / \mathrm{g}$ & \multirow{3}{*}{$\begin{array}{l}\mathrm{pH}_{\mathrm{PZC}}(\mathrm{Com} / \mathrm{CN} 1)=5.1 \\
\mathrm{pH}_{\mathrm{PZC}}(\mathrm{Com} / \mathrm{R})=6.5\end{array}$} \\
\hline & & Micro+mesopores & \\
\hline & & $\begin{array}{l}\text { Similar } V_{\text {micro }} \text { but } V_{\text {meso }} \text { of } \\
\text { Com/CN } 1 \text { is the double of } \\
\text { Com/R }\end{array}$ & \\
\hline & $\begin{array}{l}\text { Steam activated cork } \\
\left(^{(C o r k / S 800)^{a}}\right.\end{array}$ & $\begin{array}{l}\text { BET area }=750 \mathrm{~m}^{2} / \mathrm{g} \\
\text { Micro+mesopores }\end{array}$ & $\mathrm{pH}_{\mathrm{PZC}} \geq 11$ \\
\hline \multirow[t]{2}{*}{ Hydrochar } & $\begin{array}{l}\text { Glucose and sucrose } \\
\text { derived hydrochars } \\
(\mathrm{HG} \text { and } \mathrm{HS})^{\mathrm{c}}\end{array}$ & Non-porous & $\mathrm{pH}_{\mathrm{PZC}}=2$ \\
\hline & $\begin{array}{l}\text { Acrylic acid modified } \\
\text { sucrose-derived } \\
\text { hydrochar } \\
(\text { HSAA7\%, HSAA14\% } \\
\text { and HSAA27\%) }\end{array}$ & Non-porous & $\begin{array}{l}\mathrm{pH}_{\mathrm{PZC}} \approx 2 \\
\text { Carboxylic, lactonic } \\
\text { and phenolic groups in } \\
\text { higher percentage than } \\
\text { in non-modified HS }\end{array}$ \\
\hline \multirow{9}{*}{$\begin{array}{l}\text { Activated } \\
\text { carbons from } \\
\text { hydrochars }\end{array}$} & \multirow{5}{*}{$\begin{array}{l}\text { Glucose, fructose and } \\
\text { sucrose derived } \\
\text { nanoporous } \\
\text { hydrochars } \\
\text { npHG, npHF and } \\
\text { npHS) }\end{array}$} & $A_{\mathrm{BET}}(\mathrm{npHG})=529 \mathrm{~m}^{2} / \mathrm{g}$ & \multirow[t]{5}{*}{$\mathrm{pH}_{\mathrm{PZC}}=2.7-3.1$} \\
\hline & & $A_{\mathrm{BET}}(\mathrm{npHF})=407 \mathrm{~m}^{2} / \mathrm{g}$ & \\
\hline & & $A_{\mathrm{BET}}(\mathrm{npHS})=487 \mathrm{~m}^{2} / \mathrm{g}$ & \\
\hline & & Micro+mesopore samples & \\
\hline & & $\begin{array}{l}\text { with predominance of } \\
\text { mesopores }\end{array}$ & \\
\hline & \multirow{4}{*}{$\begin{array}{l}\text { Chemically activated } \\
\text { sucrose-derived } \\
\text { hydrochar } \\
(\mathrm{HS} / \mathrm{C} 800 \text { and } \\
\mathrm{HS} / \mathrm{H} 800)^{\mathrm{b}}\end{array}$} & $A_{\mathrm{BET}}(\mathrm{HS} / \mathrm{C} 800)=1350 \mathrm{~m}^{2} / \mathrm{g}$ & \multirow[t]{4}{*}{$\mathrm{pH}_{\mathrm{PZC}} \approx 4$} \\
\hline & & $A_{\mathrm{BET}}(\mathrm{HS} / \mathrm{H} 800)=2431 \mathrm{~m}^{2} / \mathrm{g}$ & \\
\hline & & Both microporous but & \\
\hline & & $\begin{array}{l}\mathrm{HS} / \mathrm{H} 800 V_{\text {micro }} \text { is almost the } \\
\text { double of } \mathrm{HS} / \mathrm{C} 800\end{array}$ & \\
\hline
\end{tabular}

185 a Synthesis and characterization reported in [26]

186 b Synthesis and characterization reported in [22,23]

$187{ }^{c}$ Synthesis reported in [23,24] and characterization reported in [24]

188 d Synthesis and characterization reported in [24]

\subsection{Characterization of the carbon materials}

192 were characterized by $\mathrm{N}_{2}$ adsorption isotherms at $-196{ }^{\circ} \mathrm{C}$ in an automatic

193 volumetric apparatus from Micromeritics (ASAP 2010). Before $\mathrm{N}_{2}$ adsorption- 
194 desorption the samples $(60-100 \mathrm{mg})$ were outgassed at $120 \stackrel{\circ}{ } \mathrm{C}$ overnight (ca.

$19517 \mathrm{~h}$ ) under vacuum (pressure $<10^{-2} \mathrm{~Pa}$ ). The apparent surface area, $A_{\mathrm{BET}}$, was 196 estimated from the $\mathrm{N}_{2}$ adsorption data in the $p / p^{0}$ range of the BET plot that

197 assures: positive interception on the ordinate of the BET plot $(C>0)$ and $n_{\text {ads }}(1-$

$\left.198 p / p^{0}\right)$ continuously increases with $p / p^{0}[27,28]$. The total pore volume, $V_{\text {total }}$, was

199 quantified with the Gurvich rule [29], the micropore volume, $V_{\text {micro, was }}$

200 calculated with the $\alpha_{s}$ method taking as reference the isotherm reported by

201 Rodríguez-Reinoso et al. [30]. ACRESCENTAR ultra e super... The mesopore

202 volume, $V_{\text {meso }}$, corresponds to the difference $V_{\text {total }}-V_{\text {micro }}$.

203 The surface chemistry properties of the synthesized porous hydrochars and 204 commercial PAC were assessed through the determination of the $\mathrm{pH}$ at the 205 point of zero charge, $\mathrm{pH}_{\mathrm{Pzc}}$, according to the reverse mass titration method [32] 206 using a Symphony SP70P pH meter. Diffuse reflectance infrared Fourier 207 transform (DRIFT) spectra of the porous hydrochars were recorded in a Nicolet 208 Magma-IR560 spectrometer provided with a high sensitivity mercury cadmium 209 telluride detector (MCT-A) that operates at cryogenic temperature. Each 210 spectrum was obtained using the powdered samples with no $\mathrm{KBr}$ addition and 211 corresponds to the accumulation of 256 scans, recording with a spectral

212 resolution of $2 \mathrm{~cm}^{-1}$ in the mid-IR $\left(4000-650 \mathrm{~cm}^{-1}\right)$ spectral range. The thermal 213 analysis (Setaram Labsys) was carried out on $15 \mathrm{mg}$ of sample under a 214 nitrogen flow rate of $50 \mathrm{~cm}^{3} \mathrm{~min}^{-1}$ up to a final temperature of $900 \stackrel{\circ}{\circ} \mathrm{C}$ (heating 215 rate of $\left.15{ }^{\circ} \mathrm{C} \mathrm{min}^{-1}\right)$. The ash content of the glucose-derived porous char was 216 determined in the same equipment after exposure of the sample at $600{ }^{\circ} \mathrm{C}$ in air $217\left(50 \mathrm{~cm}^{3} \mathrm{~min}^{-1}\right)$ for $3 \mathrm{~h}$ (constant mass). 
218 The morphology of the porous hydrochars was evaluated by Scanning

219 Electron Microscopy (SEM) performed at a Zeiss Supra 55 VP apparatus with 5 $220 \mathrm{kV}$ as accelerating voltage and using the powdered samples coated with 221 iridium.

\subsection{Standard preparation and water samples}

Stock solutions of individual analytes $\left(1,000.0 \mathrm{mg} \mathrm{L}^{-1}\right)$ used for the working standard mixture were prepared in $\mathrm{MeOH}$ and stored at $4 \stackrel{\circ}{\circ} \mathrm{C}$ and renewed every month. Working standard mixtures of $1.0 \mathrm{mg} \mathrm{L}^{-1}$ were daily prepared in $\mathrm{MeOH}$ and used for spiking sample assays. For instrumental calibration, standard mixtures were prepared in $\mathrm{MeOH}$ by appropriate dilution from stock solutions.

The water samples were obtained in the metropolitan area of Lisbon

230 (Portugal). The sea water samples were collected in the coastal area near

231 Estoril and Costa da Caparica, the lake water from an artificial lake (Campo 232 Grande) and the tap water samples from the public water supply system of

233 Lisbon and Almada. The estuarine water samples were collected at Ponta do 234 Mato, a Tagus river estuary beach. The wastewater treatment plant (WWTP) 235 samples were obtained from Alcântara WWTP after primary decantation and 236 filtration. All samples were collected in clean amber glass bottles and filtered 237 with paper filters (125 mm of diameter, $10-13 \mu \mathrm{m}$ of pore size, Cat No 1001 125, 238 Whatman; Amersham, U.K.) and kept refrigerated at $-20 \stackrel{\circ}{\mathrm{C}}$ until being used.

\section{$2.5 B A \mu E-\mu L D$ methodology}

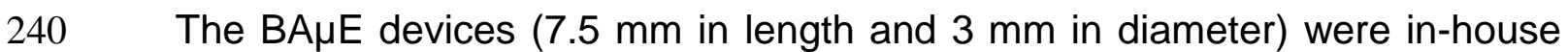
241 prepared as indicated in previous works [17,33]. After being produced, the 
242 devices were stored at room temperature in closed glass flasks. The BA $\mu \mathrm{E}$

243 devices were cleaned with $\mathrm{MeOH}$ and ultra-pure water before use. Considering

244 that microextraction bars are relatively inexpensive and easy to prepare, and

245 aiming to avoid any possible contamination, they were discarded after each 246 use.

247 The $\mathrm{BA} \mu \mathrm{E}-\mu \mathrm{LD}$ procedure was performed by placing a $25 \mathrm{~mL}$ aliquot of the 248 water samples in a $25 \mathrm{~mL}$ sampling glass flask, followed by the introduction of a

249 BA $\mu \mathrm{E}$ device, previously coated with $\mathrm{npHS}$, and a conventional Teflon magnetic 250 stirring bar. The assays were performed in a multipoint agitation plate 251 (Variomag $\mathrm{H}+\mathrm{P}$ Labortechnik Multipoint 15, Oberschleissheim, Germany) at 252 room temperature using $1,000 \mathrm{rpm}$ for $16 \mathrm{~h}(\mathrm{pH} 2.0)$. After microextraction, the 253 devices were removed from the samples with clean tweezers, dried for a few seconds using a lint-free tissue and placed into glass vial inserts containing 100 $\mu \mathrm{L}$ of $\mathrm{ACN}$, ensuring their total immersion prior to ultrasonic treatment (Branson 3510, Zurich, Switzerland) at room temperature for $60 \mathrm{~min}$. After $\mu L D$, the

257 devices were removed, $100 \mu \mathrm{L}$ of ultra-pure water was added, the vials 258 vortexed for $10 \mathrm{~s}$, and closed, followed by HPLC-DAD analysis. The standard 259 addition method (SAM) was applied in real samples assays using four 260 concentration levels ranging from $8.0 \mu \mathrm{g} \mathrm{L}^{-1}$ to $104.0 \mu \mathrm{g} \mathrm{\textrm {L } ^ { - 1 }}$ for all PhCs under 261 study. Blank assays were also performed using the same procedure but without 262 spiking ("zero-point" assays). The assays on real matrices were performed in 263 triplicate.

\subsection{Instrumental set-up}

HPLC-DAD analysis were carried out on a benchtop Agilent 1100 series LC 
267 equipped with a vacuum degasser (G1322A), autosampler (G1313A), 268 thermostated column compartment (G1316A), quaternary pump (G1311A) and 269 a diode array detector (G1315B). The data acquisition and system control were 270 performed by the software LC3D ChemStation (version Rev.A.10.02[1757], 271 Agilent Technologies). Analyses were performed on a Kinetex hexyl phenyl 272 column, $150.0 \times 4.6 \mathrm{~mm}, 2.6 \mu \mathrm{m}$ particle size (Phenomenex, Torrence, U.S.A.).

273 The samples were analysed using a gradient mobile phase consisting of $2.5 \%$ 274 acetic acid/ultra-pure water (v/v, solvent A) and ACN (solvent B). The employed 275 elution gradient was as follows: 0 min - 80/20 (solvent $A / B$ ); $24 \min -20 / 80$ 276 (solvent $A / B$ ); 27 min - 20/80 (solvent $A / B$ ); 30 min - 80/20 (solvent $A / B$ ); 35 min $277-80 / 20$ (solvent A/B). All solvents were previously filtered (125 $\mathrm{mm}$ in diameter, 278 10-13 $\mu \mathrm{m}$ in pore size, 1001 125, Whatman, U.K.) to remove suspended 279 particles, if any. The detector was set at $280 \mathrm{~nm}$ and the column temperature at $28020 \stackrel{\circ}{ } \mathrm{C}$. The injection volume was $40 \mu \mathrm{L}$ with a draw speed of $200 \mu \mathrm{L} \mathrm{min}{ }^{-1}$ and 281 the flow rate was set at $0.6 \mathrm{~mL} \mathrm{~min}^{-1}$. For identification purposes, standard 282 addition was used, by spiking the samples with pure standards, as well as by 283 comparing the relative retention time and peak purity with the $\mathrm{UV} / \mathrm{Vis}$ spectral 284 reference data. For quantification purposes, calibration curves using the 285 external standard methodology were performed. Instrument linearity was 286 calculated by injecting ten standard solutions having concentration from 10.0 or $28730.0 \mu \mathrm{g} \mathrm{L}^{-1}$ (depending on the compound) to 5,000.0 $\mathrm{gg} \mathrm{L}^{-1}$, where it was 288 possible obtain determination coefficients $\left(r^{2}\right)$ higher than 0.99 for the target 289 compounds. For recovery calculations, peak areas obtained from each assay 290 were compared with the peak areas of standard controls used for spiking. Peak 291 areas were obtained by integration of each target compounds corresponding 
292 peak using the mentioned software. The sensitivity of the instrumental system 293 was checked through the limits of detection (LODs) and quantification (LOQs)

294 calculated with signal-to-noise $(\mathrm{S} / \mathrm{N})$ of $3 / 1$ and $10 / 1$, where it ranged from 1.0 $295 \mu \mathrm{g} \mathrm{L}^{-1}$ to $10.0 \mu \mathrm{g} \mathrm{L}^{-1}$ and between $5.0 \mu \mathrm{g} \mathrm{L}^{-1}$ to $27.0 \mu \mathrm{g} \mathrm{L}^{-1}$ for all the PhCs under

296 study, respectively. The instrumental precision was evaluated by consecutively

297 injecting a standard mixture $\left(n=6,1.0 \mathrm{mg} \mathrm{L}^{-1}\right)$, resulting in relative standard 298 deviations (RSD) lower than $2.9 \%$.

\section{Results and discussion}

\subsection{Carbon material selectivity as sorbent coating}

To maximize the microextraction efficiency by the BA $\mu \mathrm{E}-\mu \mathrm{LD}$ process, thirteen carbon materials were tested as enrichment phase for the recovery of

304 PhCs using carbamazepine, 17a-ethinylestradiol, 17ß-estradiol, diclofenac and triclosan as model compounds. These carbon materials were selected to cover a large range of textural features (from non-porous to highly porous samples with $A_{\mathrm{BET}}$ up to $2400 \mathrm{~m}^{2} / \mathrm{g}$ ) and surface properties (acidic, neutral or basic, with

$308 \mathrm{pH}_{\mathrm{PZC}}$ ranging from 2 to 11 ), as it can be observed in tables 1 and 2. Additional 309 information on the physicochemical properties of the studied carbons is summarized in the Supporting Information (topic S1). The evaluation assays

311 were made in triplicate using ultra-pure water samples spiked at the $16.0 \mathrm{\mu g} \mathrm{L}^{-1}$ 312 level.

As presented in figure $2 \mathrm{a}$, the recovery efficiency of the carbon materials

314 for the five selected PhCs is strongly dependent on both the type of material 315 and the target pharmaceutical compound. 
317 Table 2 - Textural properties of the porous hydrochars and commercial activated carbons, and $318 \mathrm{pH}_{\mathrm{PZC}}$.

\begin{tabular}{|c|c|c|c|c|c|c|c|}
\hline \multirow[b]{2}{*}{ Sample } & \multirow[b]{2}{*}{$\underset{\left(\mathrm{m}^{2} \mathrm{~g}^{-1}\right)}{\boldsymbol{A}_{\mathrm{B} \mathrm{T}}}$} & \multirow{2}{*}{$\begin{array}{c}V_{\text {total }}{ }^{\mathrm{a}} \\
\left(\mathrm{cm}^{3} \mathrm{~g}^{-1}\right)\end{array}$} & \multirow{2}{*}{$\begin{array}{c}V_{\text {meso }}{ }^{b} \\
\left(\mathrm{~cm}^{3} \mathrm{~g}^{-1}\right)\end{array}$} & \multicolumn{3}{|c|}{$\alpha_{s}$ Method } & \multirow[b]{2}{*}{$\mathrm{pH}_{\mathrm{PZC}}$} \\
\hline & & & & $\begin{array}{l}V_{\alpha} \text { total } \\
\left(\mathrm{cm}^{3} \mathrm{~g}^{-1}\right)\end{array}$ & $\begin{array}{c}V_{\alpha \text { ultra }} \\
\left(\mathrm{cm}^{3} \mathrm{~g}^{-1}\right)\end{array}$ & $\begin{array}{l}V_{\alpha \text { super }} \\
\left(\mathrm{cm}^{3} \mathrm{~g}^{-1}\right)\end{array}$ & \\
\hline npHG & 529 & 0.58 & 0.47 & 0.11 & 0.00 & 0.11 & 3.0 \\
\hline npHF & 407 & 0.28 & 0.16 & 0.12 & 0.00 & 0.12 & 2.7 \\
\hline npHS & 487 & 0.47 & 0.35 & 0.12 & 0.00 & 0.12 & 3.1 \\
\hline Com/CN1 & 1179 & 0.98 & 0.68 & 0.30 & 0.00 & 0.30 & 5.1 \\
\hline Com/R & 964 & 0.65 & 0.37 & 0.28 & 0.10 & 0.18 & 6.5 \\
\hline
\end{tabular}

${ }^{a}$ Evaluated at $p / p^{0}=0.975$ in the $\mathrm{N}_{2}$ adsorption isotherms at $-196{ }^{\circ} \mathrm{C}$

${ }^{\mathrm{b}}$ Difference between $V_{\text {total }}$ and $V_{\alpha \text { total }}$

From the set of activated carbons tested (samples Com/CN1, Com/R,

323 Cork/S800, HS/C800 and HS/H800), the commercial sample Com/CN1 with a

324 BET area higher than $1000 \mathrm{~m}^{2} / \mathrm{g}$, a micro+mesopore structure and slightly acidic character (i.e., $\mathrm{pH}_{\mathrm{PzC}}$ of 5.1) outperformed the steam activated cork carbon (sample Cork/S800) with lower surface area and basic character, as well as the activated sucrose-derived hydrochars (samples $\mathrm{HS} / \mathrm{H} 800$ and $\mathrm{HS} / \mathrm{C} 800$ ) with a better-developed micropore structure and acidic nature. The non-porous hydrochars (figure $2 \mathrm{~b}$ ) failed to recover diclofenac and, while the samples HG and HS were able to recover ca. $40 \%$ of the remaining PhCs, the acrylic acid

331 modified hydrochars (HSAAx\%) failed the recovery of $17 \alpha$-ethinylestradiol and

$33217 \beta$-estradiol. On the contrary, the acidic nanoporous hydrochars (figure 2c)

333 displaying micro-/mesopore networks and moderate surface areas (Tables 1

334 and 2) allowed to recover the five target PhCs. Furthermore, the bar prepared

335 using sample npHS as coating allowed to obtain recoveries comparable to the

336 best commercial activated carbon for all the PhCs (ranging between 42-78\%),

337 with the exception of carbamazepine. 
338
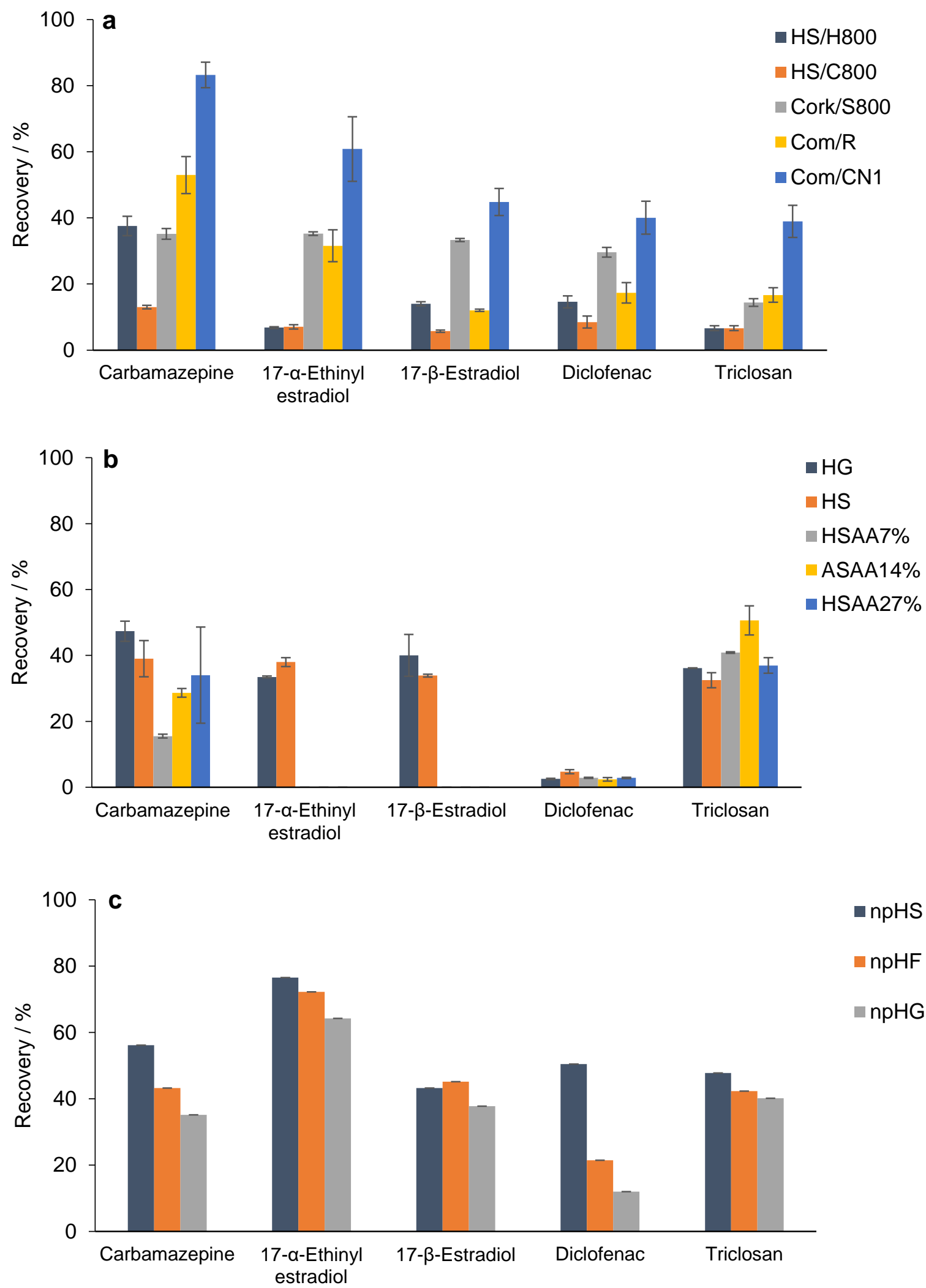

Figure 2 - Effect of sorbent selectivity on the recovery yields of the five mentioned PhCs using commercial and lab-made activated carbons (a), lab-made hydrochars (b) and lab-made nanoporous hydrochars (c) as sorbent coating obtained by BA $\mu E-\mu L D / H P L C-D A D$. BA $\mu E$ coating: 1.0-3.0 mg; Spiking level: $16.0 \mu \mathrm{g} \mathrm{L}^{-1}$; Equilibrium: $16 \mathrm{~h}$ (1000 rpm) pH 5.5; $\mu \mathrm{LD}$ : ACN $(100 \mu \mathrm{L}) 60 \mathrm{~min}$. 
To gather a deeper understanding of the contribution of the adsorption

349 and desorption processes in the overall recovery of the lowest performing

350 materials, three of them were selected for a complementary assay. Samples $\mathrm{HS} / \mathrm{H} 800$, HG and HSAA27\% were tested for the recovery of the five PhCs using higher initial concentrations, thereby facilitating the quantification after the concentration step (figure S3, SI). In the case of sample $\mathrm{HS} / \mathrm{H} 800$

354 (superactivated carbon), the low recoveries can be attributed to the irreversible 355 adsorption of the targets inside the well-developed microporous structure; on 356 the contrary, for the non-porous hydrochars, most of the molecules remain in

357 the water matrix, thus the less efficient recovery of polar PhCs seems to be 358 related with their low affinity towards the carbon coating phase. Under these 359 experimental conditions, recoveries of $100 \%$ were obtained for triclosan -the 360 most nonpolar target- with these non-porous hydrochars, whereas the recovery 361 of carbamazepine -the most polar compound of the set- would be hindered by 362 the irreversible retention on the acidic surface of such carbon coatings. 363 Interestingly, the relatively high recoveries of herein prepared nanoporous

364 hydrochars characterized by lower surface areas than commercial activated 365 carbons (tables 1 and 2) points out to the paramount importance of combining 366 micro-mesoporosity and appropriate surface chemistry. The porous hydrochars 367 are composed by agglomerates of interconnected units in the nanometric scale $368(20-50 \mathrm{~nm})$ that originate a pore system in the mesoscale (figure 3$)$. This 369 could be important to assure an efficient and fast adsorption and desorption of 370 the target compounds during the enrichment step. 

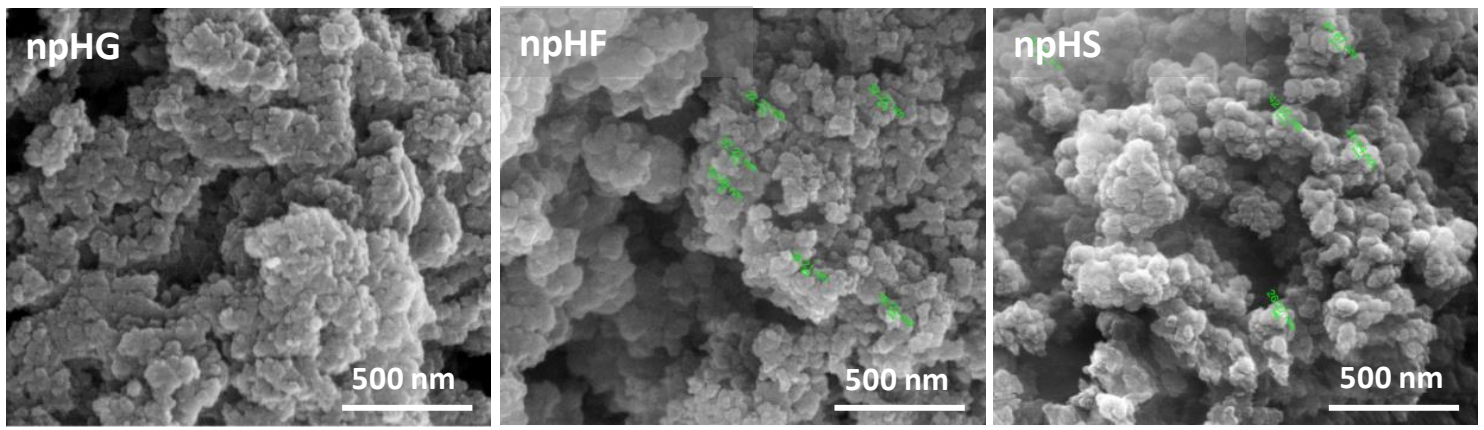

Figure 3 - SEM images of the nanoporous hydrochars.

Figure 4 illustrates the influence of the properties of the above mentioned thirteen carbon materials on their performance as enrichment phases. The four graphics present the correlation between selected carbon properties $\left(\mathrm{pH}_{\mathrm{PZC}}\right.$ vs $A_{\mathrm{BET}}, V_{\text {total }}, \% V_{\text {micro }}$ and $\left.\% V_{\text {meso }}\right)$ and the percentage of removal attained for the set of five PhCs (carbamazepine, 17a-ethinylestradiol, 17ß-estradiol, diclofenac and triclosan). The number of occurrences corresponding to removals in the

379 first quartile is systematically higher at low $\mathrm{pH}_{\mathrm{PzC}}$ values associated with 380 percentages of micropores between $15 \%$ and $50 \%$ and consequently to the presence of a micro+mesopore network.

Summarising, these set of data points out that the selection of an 383 adequate carbon coating for $B A \mu E-\mu L D / H P L C-D A D$ to assure high recoveries should consider sorbents combining a well-developed pore structure in the full micro to mesopore range, along with acidic surface groups (i.e. phenol and carboxylic acid, see DRIFT spectra discussion in Supporting Information).

In light of these preliminary results for the nanoporous hydrochars with 388 the set of five targets, these carbon materials were further tested as enrichment 389 phase for the recovery of the 10 PhCs and benchmarked vs two commercial 390 PACs (figure 5). As seen, under the experimental conditions tested (ca. pH 5.5)

391 none of the carbon materials were able to recover clofibric acid, although 
392 recoveries up to $50 \%$ were obtained for the other two acidic compounds

393 (diclofenac and mefenamic acid).

a

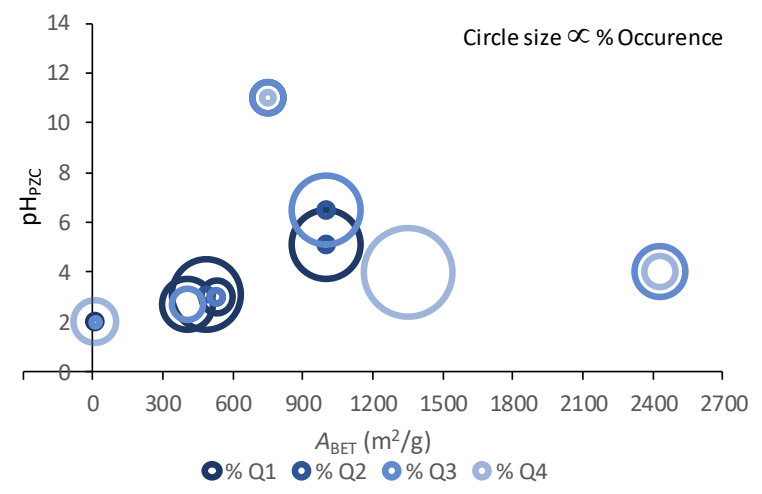

C

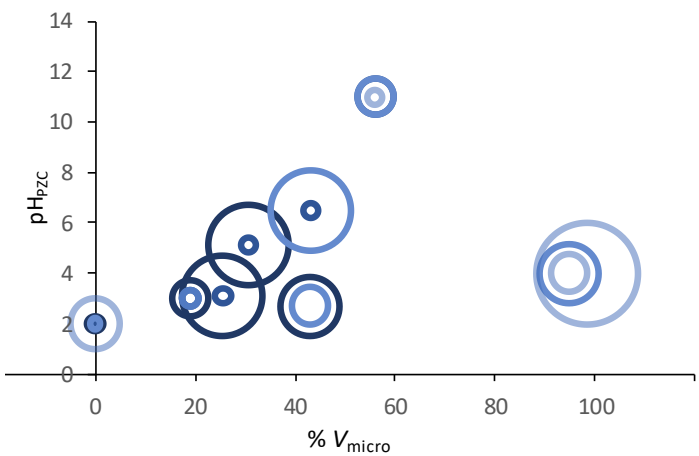

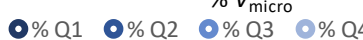

b

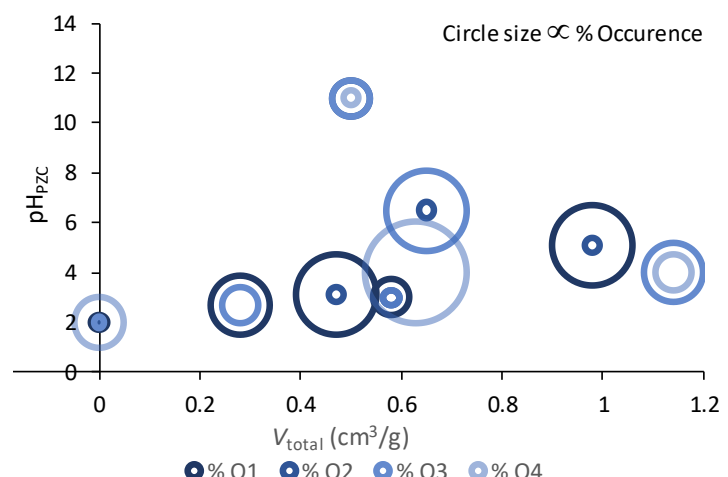

d

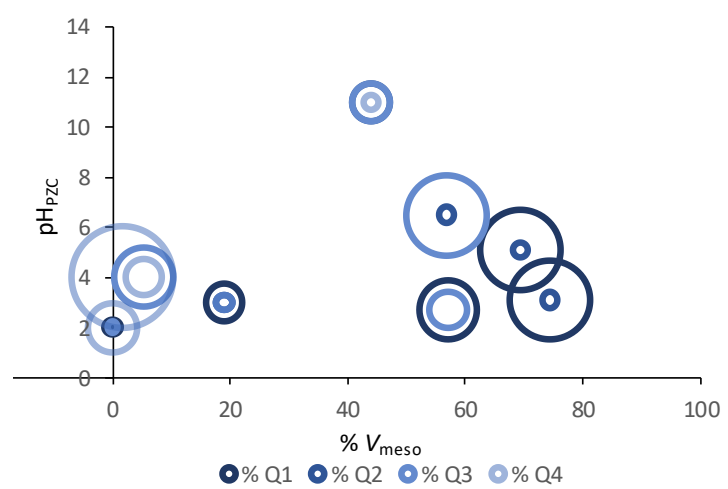

Figure 4 - Influence of carbon materials properties in the removal percentages of five target PhCs: $\mathrm{pH}$ at the point of zero charge $\left(\mathrm{pH}_{\mathrm{PZC}}\right)$ versus $\mathrm{BET}$ area $(\mathrm{a})$, total pore volume $(\mathrm{b})$, percentage of micropore volume (c), and percentage of mesopore volume (d). Circles represent the percentage of removal (in quartiles) adjusted for the removal range of each PhC, Q1 corresponding to top $25 \%$ removal and Q4 to bottom $25 \%$ removal, and circle sizes are directly proportional to the percentage of occurrence.

Com/R presented the lowest performance for the majority of PhCs, with

403 the exceptions were sulfamethoxazole and carbamazepine. Such low recoveries may be partially since this carbon was the only material displaying a slightly positively charged surface under our experimental conditions (i.e., pH solution $<\mathrm{pH}_{\mathrm{PzC}}$ 6.5). Despite a less developed pore network, the nanoporous hydrochars compare favourably with the commercial activated carbons, except

408 in the case of sulfamethoxazole and carbamazepine. This might be attributed to their negatively charged surface charge (i.e., $\mathrm{pH}$ solution $>\mathrm{pH}_{\mathrm{PzC}} 2.7-3.1$ ). For 
410 the other pharmaceuticals, the recoveries ranged between $40 \%$ (17- $\beta$-estradiol)

411 and $80 \%$ (17- $\alpha$-ethinyl estradiol and estrone), with the nanoporous

412 hydrocarbons prepared from sucrose and fructose competing closely with the

413 best performing commercial carbon (sample Com/CN1) for the majority of the

414 target compounds. Considering all this, further optimization assays were carried

415 out on microextraction bars prepared using samples npHS, npHF and

416 Com/CN1as carbon coatings.

417

418

419

420

421

422

423

424

425

426

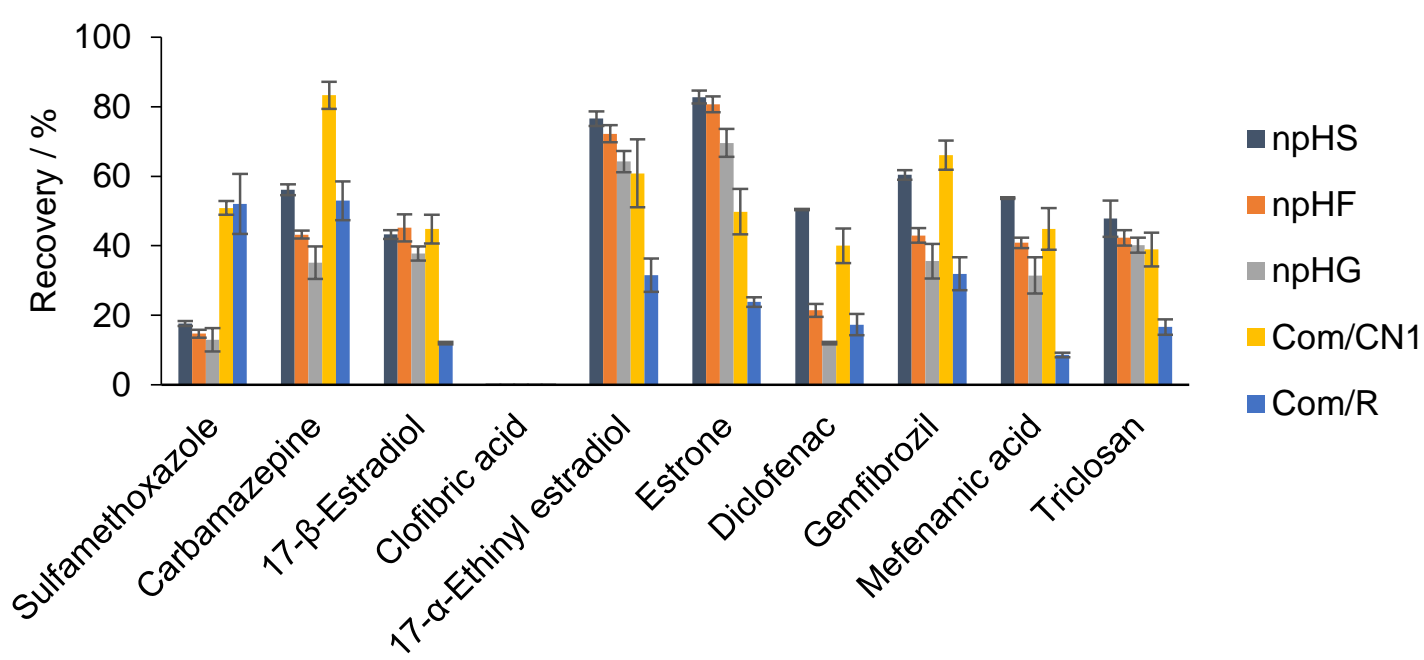

\footnotetext{
Figure 5 - Effect of sorbent selectivity on the PhCs recovery yields with different carbon based materials as sorbent coating obtained by BA $\mu \mathrm{E}-\mu \mathrm{LD} / \mathrm{HPLC}-\mathrm{DAD}$. BA $\mu \mathrm{E}$ coating: 1.0-3.0 mg; Spiking level: $16.0 \mu \mathrm{g} \mathrm{L}^{-1}$; Equilibrium: $16 \mathrm{~h}$ (1000 rpm) pH 5.5; $\mu \mathrm{LD}$ : ACN (100 $\left.\mu \mathrm{L}\right) 60 \mathrm{~min}$.
}

After choosing the best performing carbon materials through $\mathrm{BA} \mu \mathrm{E}$ for the determination of the target PhCs from aqueous media, the $\mu \mathrm{LD}$ parameters, as well as the equilibrium time, stirring rate, ionic strength, matrix polarity, and sample $\mathrm{pH}$ were also evaluated. All the results the optimization, with exception of the latter which will be discussed in the following, can be consulted in SI.

The chemical characteristics of the water matrix were also assessed, in particular $\mathrm{pH}$, ionic strength and polarity. Figure 6 shows the recovery yields 
429 obtained for the $\mathrm{BA} \mu \mathrm{E}$ devices at different solution $\mathrm{pH}$ between 2 and 10 for the

430 three selected carbon coatings. With the exception of carbamazepine recovery

431 with sample $\mathrm{CN1}$, the solution $\mathrm{pH}$ strongly influenced the recovery of all the

432 target analytes. This was somewhat expected since it is well known that this 433 parameter affects the ionic or neutral forms of the PhCs in solution [11], as well

434 as the surface charge of the carbon materials. Under strong acidic $\mathrm{pH}$, clofibric

435 acid -analyte with the lowest $\mathrm{p} K_{\mathrm{a}}$ value- was recovered with yields between 70

436 to $90 \%$ for all tested sorbent phases. This points out that the determination of

437 clofibric acid by $\mathrm{BA \mu E}$ using carbon coatings as enrichment phases, is only

438 possible when this semipolar acidic compound is in the protonated form. Our

439 previous results using cork-derived activated carbons as enrichment materials

440 also identified the critical role of $\mathrm{pH}$ in the quantification of clofibric acid, with the

441 best results attained at acidic $\mathrm{pH}$ [34].

442 The recovery yields increased at $\mathrm{pH} 2.0$ for all compounds and carbon 443 coatings used, since all the carbon materials display a slightly positively 444 charged surface under these conditions (solution $\mathrm{pH}<\mathrm{pH}_{\mathrm{PzC}}$ ). These results 445 can be rationalized considering the $\log D$ values (that corrects the $\log K_{0 / w}$ for 446 the $\mathrm{p} K_{\mathrm{a}}$ of each compound by quantifying the amount of both the ionized and 447 non-ionized forms in octanol and water, Scheme S1, SI) of the PhCs at the $\mathrm{pH}$ 448 values under study. 

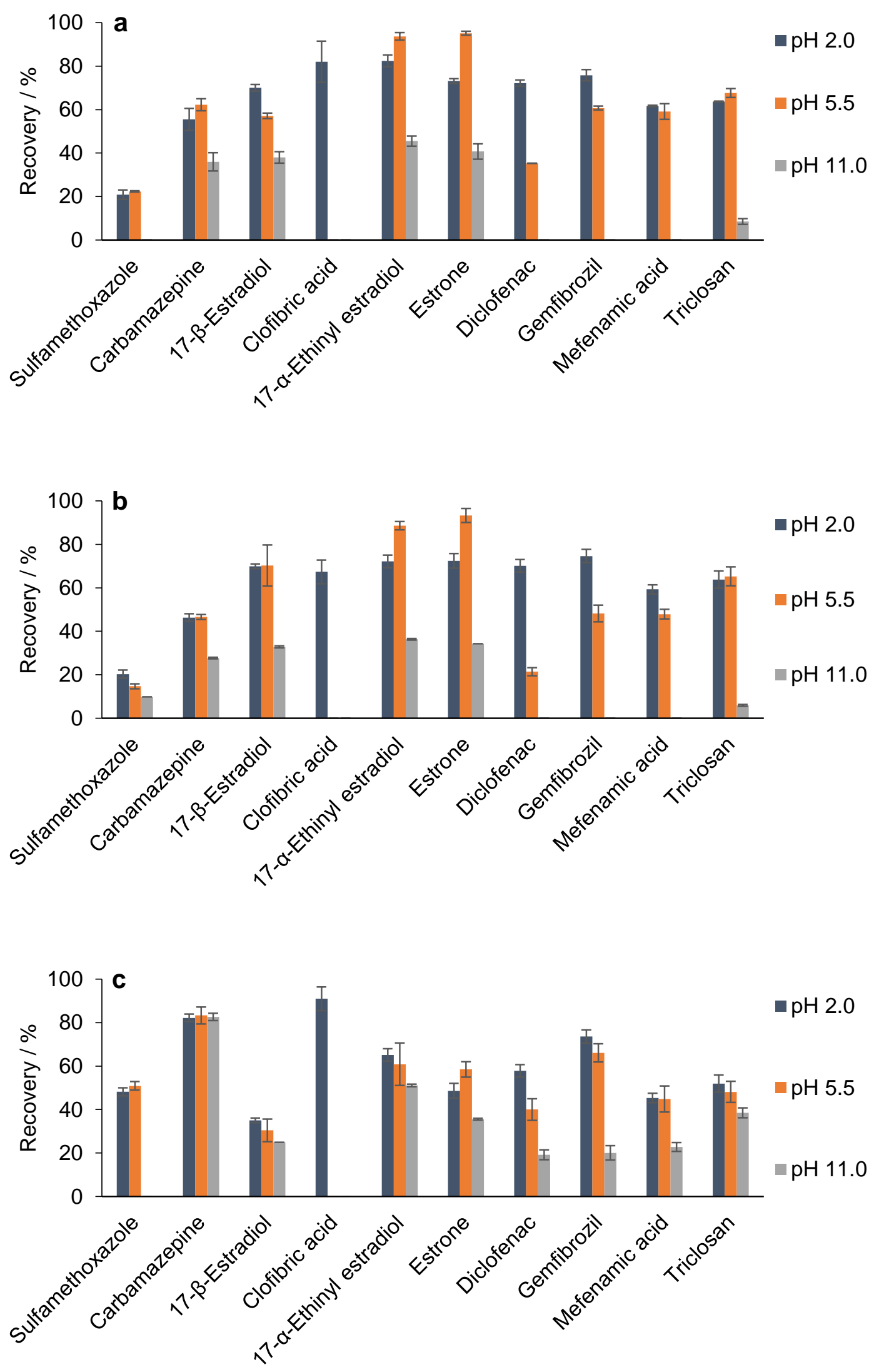

Figure 6 - Effect of matrix pH on the PhCs recovery yields using npHS (a), npHF (b) and 
Table $\mathrm{S} 1 \mathrm{(SI})$ showed that regardless the solution $\mathrm{pH}$ there is an overall increase in the recovery yields with the increase in the $\log D$ values. In general,

458 at solution $\mathrm{pH} 2.0$, the selected PhCs present higher octanol solubility (favoring both adsorption and desorption), thus contributing to higher recovery yields.

460 When the solution $\mathrm{pH}$ is higher than or similar to the $\mathrm{p} K_{\mathrm{a}}$ of a given $\mathrm{PhCs}$, its 461 recovery gets close to zero, justifying the greater reduction in the recovery 462 yields in compounds with lower $\mathrm{p} K_{\mathrm{a}}$ values. It can so be concluded that the 463 lower recoveries are related with the deprotonation of the target compounds, 464 thus with the higher stability in the water matrix and consequently lower affinity 465 towards the porous solids.

\subsection{Validation of the BA $\mathrm{BE}(\mathrm{HC}-\mathrm{S})-\mu L D / H P L C-D A D$ methodology}

By using the optimized experimental conditions for each carbon-based sorbents (Com/CN1, npHF and $\mathrm{npHS}$ ), it was possible to attain average recoveries between 20.3 and $90.9 \%$ for all target compounds in ultra-pure

471 water spiked at the $16.0 \mu \mathrm{g} \mathrm{L}^{-1}$ level. Comparatively, better results were 472 obtained using npHS as carbon coating with most of the PhCs, thus the 473 validation assays of the $\mathrm{BA} \mu \mathrm{E}(\mathrm{npHS})-\mu \mathrm{LD} / \mathrm{HPLC}-\mathrm{DAD}$ methodology were 474 carried out using this sorbent phase (table S1, SI).

475 The sensitivity of the methodology was checked through the LODs (0.5 $\left.4761.5 \mu \mathrm{g} \mathrm{L}^{-1}\right)$ and LOQs $\left(1.5-5.0 \mu \mathrm{g} \mathrm{L}^{-1}\right)$, calculated with signal to noise ratios $477 \mathrm{~S} / \mathrm{N}$ of $3 / 1$ and $10 / 1$, respectively. The methodology was also evaluated through 478 intraday and interday repeatability assays, calculating the corresponding 479 relative standard deviations (RSD) [35]. Interday repeatability assays were 
480 carried out as six replicates a day in three consecutive days and intraday 481 repeatability assays consisted in six replicates performed in the same day

482 (using three spiking levels). Good precisions were achieved for the intraday 483 repeatability assays, with $\mathrm{RSD} \leq 8.4 \%$ (diclofenac), and for interday 484 repeatability, was $\leq 12.3 \%$ (mefenamic acid), under optimized experimental 485 conditions. Assays were also performed in ultra-pure water having 486 concentrations ranging from 5.0 to $104.0 \mathrm{\mu g} \mathrm{L}^{-1}$, where convenient linearity was 487 obtained, with $r^{2}$ higher than 0.99 for all the target PhCs under study. Table S2 488 (SI) summarizes the LODs, LOQs, as well as intraday and interday precision 489 levels achieved by the proposed methodology, under optimized experimental 490 conditions.

\subsection{Performance comparison with other microextraction techniques}

A comparison of the performance of the $B A \mu E(n p H S)-\mu L D / H P L C-D A D$ methodology and other established static-based microextraction techniques is shown in table 3 [36-44]. As it can be observed, the developed methodology using $\mathrm{BA} \mu \mathrm{E}$ devices coated with sucrose-based hydrochar presents similar or

497 better recovery yields than other miniaturized enrichment techniques, e.g., 498 SBSE coated with PDMS, PA or EG [38] or SBME coated with C8 polymer [39] 499 for the extraction of carbamazepine; TFME coated with PDMS [44] for the

500 extraction of 17- $\beta$-estradiol; SBSE coated with PDMS [42] for the extraction of 501 clofibric acid; SBSE coated with PU [45] for the extraction of diclofenac, 502 gemfibrozil or mefenamic acid. Additionally, the BA $\mu \mathrm{E}(\mathrm{npHS})-\mu \mathrm{LD} / \mathrm{HPLC}-\mathrm{DAD}$ 503 methodology sensitivity is similar when compared to analogue instrumental 504 systems $[37,39,45]$ and/or some mass spectrometry or tandem mass 
505 spectrometry instrumental systems $[40,44]$. On the other hand, instrumental

506 apparatus that employ mass spectrometry or tandem mass spectrometry

507 expectedly presented lower LODs than the proposed technique $[38,41,44,46]$.

508 
$510 \quad$ PhCs in aqueous samples.

\begin{tabular}{|c|c|c|c|c|c|}
\hline PPCP & $\begin{array}{c}\text { Static based microextraction } \\
\text { techniques }\end{array}$ & Instrumental system & $\begin{array}{l}\text { Recovery } \\
(\%)\end{array}$ & $\begin{array}{l}\text { LOD } \\
\left(\mu \mathrm{L} \mathrm{L}^{-1}\right)\end{array}$ & Refs. \\
\hline \multirow{3}{*}{ Sulfamethoxazole } & SPME(CW/TPR) & LC-(ESI)MS/MS & 59.2 & 14.0 & [36] \\
\hline & MEPS(C8) & \multirow{2}{*}{ HPLC-DAD } & n.a. & LOQ: 5.0 & [37] \\
\hline & $\mathrm{BA} \mu \mathrm{E}(\mathrm{npHS})$ & & 20.9 & 1.5 & This work \\
\hline \multirow{4}{*}{ Carbamazepine } & SBSE(PDMS, PA or EG) & LC-(ESI)MS/MS & $<1.0$ & $\mathrm{n} / \mathrm{a}$ & [38] \\
\hline & TFME(PDMS) & GC-MS & 67.1 & 0.72 & [44] \\
\hline & SBME(C8) & HPLC-UV & $35.0-42.0$ & 0.7 & [39] \\
\hline & $\mathrm{BA \mu E}(\mathrm{npHS})$ & HPLC-DAD & 55.5 & 0.5 & This work \\
\hline \multirow{5}{*}{$17-\beta$-Estradiol } & SBSE(PDMS) & LDTD/APCI-MS/MS & $\sim 40.0$ & 2.8 & [40] \\
\hline & TFME(PDMS) & \multirow{3}{*}{ GC-MS } & 85.0 & 0.41 & [44] \\
\hline & SPME(PA) & & $92.0-101.0$ & 0.15 & [41] \\
\hline & SBSE(PDMS) & & 7.0 & 0.853 & [46] \\
\hline & $\mathrm{BA} \mu \mathrm{E}(\mathrm{npHS})$ & HPLC-DAD & 70.0 & 2.0 & This work \\
\hline \multirow{2}{*}{ Clofibric acid } & SPME(PA) & \multirow{2}{*}{ GC-MS } & $95.0-98.0$ & 0.75 & [41] \\
\hline & SBSE(PDMS) & & 18.5 & 0.222 & [46] \\
\hline
\end{tabular}




\begin{tabular}{|c|c|c|c|c|c|}
\hline & $\mathrm{BA} \mu \mathrm{E}(\mathrm{AC})$ & & $79.7-96.1$ & $0.21-0.28$ & [34] \\
\hline & $\mathrm{BA \mu E}(\mathrm{npHS})$ & 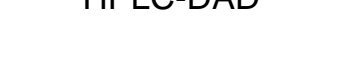 & 82.0 & 2.5 & This work \\
\hline \multirow{4}{*}{$\begin{array}{c}17-\alpha- \\
\text { Ethinylestradiol }\end{array}$} & SBSE(PDMS) & LDTD/APCI-MS/MS & $\sim 30.0$ & 2.6 & {$[40]$} \\
\hline & SPME(PA) & \multirow{2}{*}{ GC-MS } & $93.0-105.0$ & 0.15 & [41] \\
\hline & SBSE(PDMS) & & 9.0 & 0.508 & [46] \\
\hline & $\mathrm{BA} \mu \mathrm{E}(\mathrm{npHS})$ & HPLC-DAD & 82.4 & 2.0 & This work \\
\hline \multirow{4}{*}{ Estrone } & SBSE(PDMS) & LDTD/APCI-MS/MS & $\sim 50.0$ & 2.2 & [40] \\
\hline & SPME(PA) & \multirow{2}{*}{ GC-MS } & $92.0-99.0$ & 0.15 & [41] \\
\hline & SBSE(PDMS) & & 12.7 & 0.789 & [46] \\
\hline & $\mathrm{BA} \mu \mathrm{E}(\mathrm{npHS})$ & HPLC-DAD & 73.1 & 2.0 & This work \\
\hline \multirow{6}{*}{ Diclofenac } & SBSE(PDMS, PA or EG) & LC-(ESI)MS/MS & $<1.0$ & $\mathrm{n} / \mathrm{a}$ & [38] \\
\hline & SBSE(PDMS) & GC-MS & 21.0 & 0.037 & [46] \\
\hline & SBSE(PDMS) & \multirow{4}{*}{ HPLC-DAD } & 34.6 & 1.6 & \multirow{2}{*}{ [45] } \\
\hline & SBSE(PU) & & 77.7 & 0.7 & \\
\hline & SBME(C8) & & $47.0-52.0$ & 0.9 & [39] \\
\hline & $\mathrm{BA} \mu \mathrm{E}(\mathrm{npHS})$ & & 72.2 & 0.5 & This work \\
\hline \multirow{3}{*}{ Gemfibrozil } & SBSE(PDMS) & GC-MS & 15.5 & 0.013 & [46] \\
\hline & SBSE(PDMS) & \multirow{2}{*}{ HPLC-DAD } & 73.4 & 1.7 & \multirow{2}{*}{ [45] } \\
\hline & SBSE(PU) & & 84.0 & 0.7 & \\
\hline
\end{tabular}




\begin{tabular}{|c|c|c|c|c|c|}
\hline & $\mathrm{BA} \mu \mathrm{E}(\mathrm{HC}-\mathrm{S})$ & & 75.8 & 1.0 & This work \\
\hline \multirow{4}{*}{ Mefenamic acid } & SBSE(PDMS) & GC-MS) & 29.0 & 0.001 & [46] \\
\hline & SBSE(PDMS) & \multirow{3}{*}{ HPLC-DAD } & 71.3 & 1.5 & \multirow{2}{*}{ [45] } \\
\hline & SBSE(PU) & & 48.4 & 1.3 & \\
\hline & $\mathrm{BA \mu E}(\mathrm{npHS})$ & & 61.7 & 0.5 & This work \\
\hline \multirow{4}{*}{ Triclosan } & SBSE(PDMS, PA or EG) & LC-(ESI)MS/MS & $40.0-80.0$ & $0.005-0.010$ & [38] \\
\hline & SPME(PA) & \multirow{2}{*}{ GC-MS } & $76.0-88.0$ & 0.15 & [41] \\
\hline & SBSE(PDMS) & & 23.8 & 0.0002 & [46] \\
\hline & $\mathrm{BA} \mu \mathrm{E}(\mathrm{npHS})$ & HPLC-DAD & 63.7 & 1.0 & This work \\
\hline
\end{tabular}

511 CW/TPR: Carbowax-templated resin; LC-(ESI)MS/MS: Liquid chromatography coupled to tandem mass spectrometry with electrospray ionization;

512 LDTD/APCI-MS/MS: Laser diode thermal desorption atmospheric pressure chemical ionization tandem mass spectrometry; MEPS: Microextraction by packed

513 sorbent; PA: Polyacrylate; PDMS: Polydimethylsiloxane; PEG: Polyethylene glycol; PU: Polyurethane; SBME: Solid bar microextraction; TFME: Thin-film

514 microextraction; 


\subsection{Application to environmental water matrices}

518 To evaluate the applicability of $B A \mu E(n p H S)-\mu L D / H P L C-D A D$ methodology

519 to real matrices, assays were performed in sea, lake, estuarine, tap and WWTP

520 water samples, through the SAM. This approach is usually the best strategy for

521 quantification purposes to determine the levels of analytes under study and to

522 reduce possible matrix interferences in real samples $[11,12,47]$. In a first step,

523 the water matrices were spiked with four working standards to produce the

524 corresponding spiking levels $\left(8.0 \mu \mathrm{g} \mathrm{L}^{-1}\right.$ to $\left.104.0 \mu \mathrm{g} \mathrm{L}^{-1}\right)$ for the ten PhCs under

525 study. "Zero-point" assays were also performed without spiking to ensure

526 maximum control of the analytical methodology. Good linear correlations were

527 achieved, with $r^{2}$ higher than 0.99 . The chromatograms of neat standard mix at

528 the $8.0 \mu \mathrm{g} \mathrm{L}^{-1}$ level for the ten PhCs (figure 7a) and WWTP sample without

529 spiking obtained by $B A \mu E(n p H S)-\mu L D / H P L C-D A D$, under optimized

530 experimental conditions (figure $7 \mathrm{~b}$ ), exemplify the results obtained proving high

531 sensitivity at the trace level. The proposed methodology allowed to quantify two

532 of the analytes under study in the WWTP sample (carbamazepine: $4.01 \pm 0.46$

$533 \mu \mathrm{g} \mathrm{L}^{-1}$; diclofenac: $\left.1.99 \pm 0.21 \mu \mathrm{g} \mathrm{L}^{-1}\right)$. 


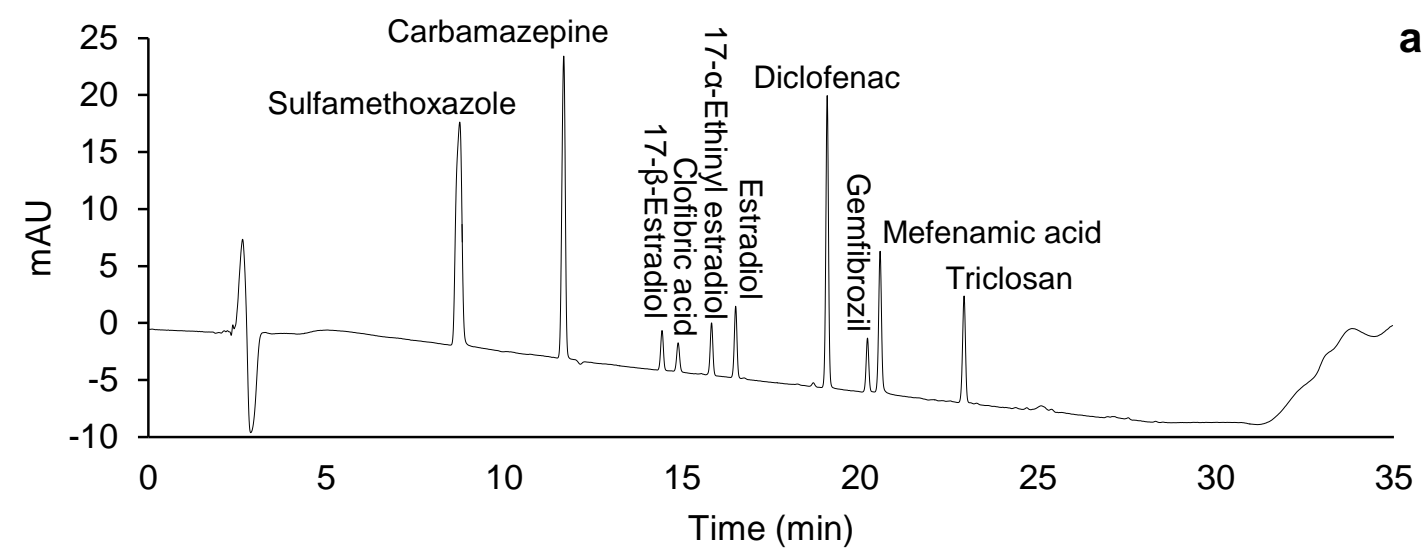

536

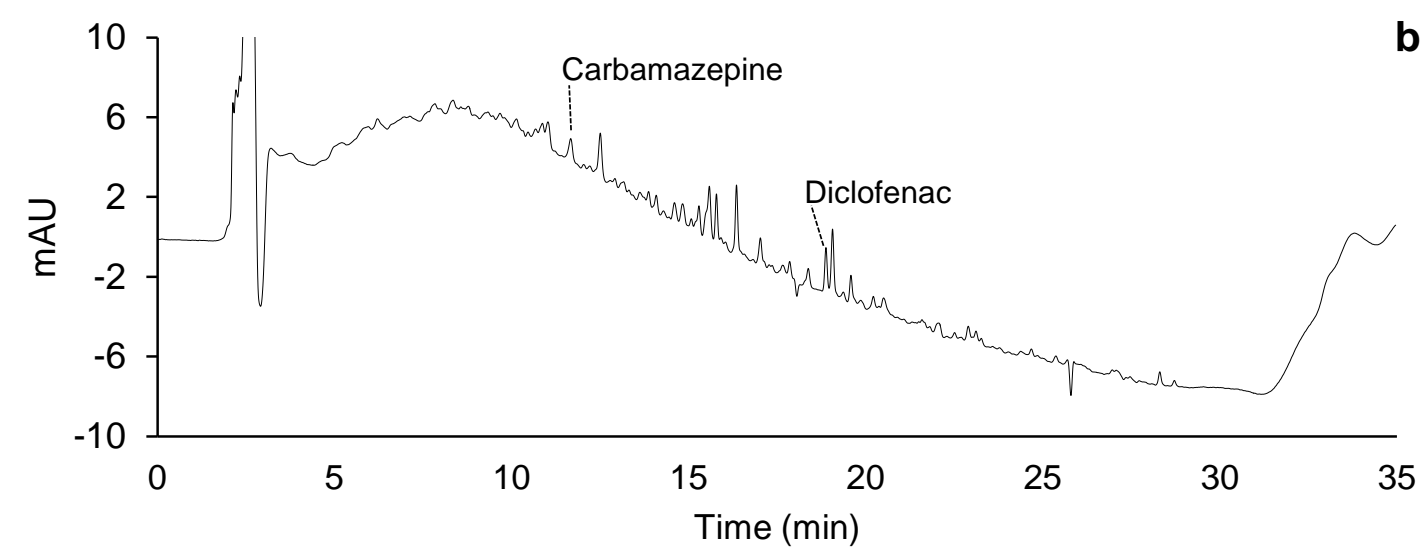

537

$538 \quad$ Figure 7 - Chromatograms obtained from assays performed on an ultrapure water sample 539 spiked at the $16.0 \mu \mathrm{g} \mathrm{L}^{-1}$ level (a) and a non-spiked WWTP sample (b), performed and by $540 \quad \mathrm{BA} \mu \mathrm{E}(\mathrm{npHS})-\mu \mathrm{LD} / \mathrm{HPLC}-\mathrm{DAD}$, under optimized experimental conditions.

541

542

4. Concluding remarks

543 Thirteen carbon sorbents prepared from different precursors and

544 methodologies - commercial activated carbons, hydrochars and nanoporous

545 hydrochars, and superactivated carbons - were tested as sorbent coatings for

546 bar adsorptive microextraction followed by microliquid desorption and high

547 performance liquid chromatography-diode array detection (BA $\mu E(n p H S)$ -

$548 \mu$ LD/HPLC-DAD methodology) for the simultaneous determination of traces of 
549 ten PhCs from distinct therapeutic classes in synthetic and environmental water

550 matrices.

551 The lab-made nanoporous hydrochars proved to compete with commercial 552 activated carbon adsorbents for the enrichment of the PhCs, due to a 553 hierarchical pore structure in the full micro-mesopore range combined with a 554 rich surface chemistry composed of acid O-groups that favour both the 555 adsorption and desorption of the target compounds, thus contributing to a high 556 performance at the trace level. The method also demonstrated to be an 557 environmentally friendly approach, easy to implement, sensitive, robust and 558 requiring low sample volume. In short, the proposed analytical methodology 559 seems to be a very effective microextraction-based alternative to fulfill the EU 560 Decision 2015/495, as well as the USEPA guidelines for PhCs monitoring, 561 particularly if combined with tandem mass spectrometry systems, which may 562 provide even better detection limits.

\section{Conflicts of Interest}

The authors declare no conflict of interest.

\section{Acknowledgments}

568 The authors wish to thank Fundação para a Ciência e a Tecnologia (FCT, 569 Portugal) for funding Centro de Química e Bioquímica (UID/MULTI/00612/2019) 570 and Centro de Química Estrutural (Pluriannual funding 2020-2023). SMA thanks

571 FCT for the PhD grant (SFRH/BD/107892/2015), ASM acknowledges FCT for 
572 the financial support to the EMBRACE project (CEECIND/01371/2017) and

573 NRN acknowledges FCT for the financial support through the contract 574 established from DL 57/2016. The authors also wish to thank Salmon \& Cia

575 (Portugal) for offering the commercial Norit carbon material.

576

577

\section{References}

578 [1] L. Arpin-Pont, M.J. Martínez-Bueno, E. Gomez, H. Fenet, Occurrence of 579

580 PPCPs in the marine environment: a review, Environ. Sci. Pollut. Res. 23 (2016) 4978-4991. doi:10.1007/s11356-014-3617-x.

581

[2] A.B. Caracciolo, E. Topp, P. Grenni, Pharmaceuticals in the environment: 582 Biodegradation and effects on natural microbial communities. A review, $\mathrm{J}$ Pharm Biomed Anal. 106 (2015) 25-36. doi: 10.1016/j.jpba.2014.11.040.

[3] W. Mnif, A.I. Hassine, A. Bouaziz, A. Bartegi, O. Thomas, B. Roig, Effect 585 of endocrine disruptor pesticides: a review, Int J Env. Res Public Heal. 8 586 (2011) 2265-2303. doi:10.3390/ijerph8062265.

[4] W.C. Li, Occurrence, sources, and fate of pharmaceuticals in aquatic 588 environment and soil, Env. Pollut. 187 (2014) 193-201. doi: 10.1016/j.envpol.2014.01.015.

[5] R. Zhao, T. Ma, S. Li, Y. Tian, G. Zhu, Porous Aromatic Framework Modified Electrospun Fiber Membrane as a Highly Efficient and Reusable Adsorbent for Pharmaceuticals and Personal Care Products Removal, ACS Appl. Mater. Interfaces. 11 (2019) 16662-16673. doi:10.1021/acsami.9b04326. 
595 [6] S.D. Richardson, T.A. Ternes, Water Analysis: Emerging Contaminants and Current Issues, Anal. Chem. 86 (2014) 2813-2848. doi:10.1021/Ac500508t.

598

599

600

601

602

603

604

605

606

607

608

609

610

611

612

613

614

615

616

617

618

[7] J.Q. Jiang, Z. Zhou, V.K. Sharma, Occurrence, transportation, monitoring and treatment of emerging micro-pollutants in waste water - A review from global views, Microchem. J. $110 \quad$ (2013) 292-300. doi:10.1016/j.microc.2013.04.014.

[8] Directive 2013/39/EU of the European Parliament and of the Council of 12 August 2013 amending Directives 2000/60/EC and 2008/105/EC as regards priority substances in the field of water policy, Off. J. Eur. Union. L226 (2013) 1-17.

[9] Commission Implementing Decision (EU) 2015/495 of 20 March 2015 establishing a watch list of substances for Union-wide monitoring in the field of water policy pursuant to Directive 2008/105/EC of the European Parliament and of the Council, Off. J. Eur. Union. L78 (2015) 40-42.

[10] Commission Implementing Decision (EU) 2018/840 of 5 June 2018 establishing a watch list of substances for Union-wide monitoring in the field of water policy pursuant to Directive 2008/105/EC of the European Parliament and of the Council and repealing Commission Implementing Decision (EU) 2015/495, Off. J. Eur. Union. L141 (2018) 9-12.

[11] N.R. Neng, J.M.F. Nogueira, Development of a bar adsorptive microextraction-large-volume injection-gas chromatography-mass spectrometric method for pharmaceuticals and personal care products in environmental water matrices, Anal Bioanal Chem. 402 (2012) 1355- 
1364. doi:10.1007/s00216-011-5515-0.

620

621

622

623

624

625

626

627

628

629

630

631

632

633

634

635

636

637

638

639

640

641

642

[12] C. Almeida, J.M. Nogueira, Determination of trace levels of parabens in real matrices by bar adsorptive microextraction using selective sorbent phases, J Chromatogr A. $1348 \quad$ (2014) 17-26. doi:10.1016/j.chroma.2014.04.057.

[13] T.S. Oliveira, M. Murphy, N. Mendola, V. Wong, D. Carlson, L. Waring, Characterization of Pharmaceuticals and Personal Care products in hospital effluent and waste water influent/effluent by direct-injection LCMS-MS, Sci. Total Environ. 518 (2015) 459-478. doi: 10.1016/j.scitotenv.2015.02.104.

[14] J.M.F. Nogueira, Stir-bar sorptive extraction - 15 years making sample preparation more environment friendly, TrAC Trends Anal. Chem. 71 (2015) 214-223. doi:http://dx.doi.org/10.1016/j.trac.2015.05.002.

[15] J.M. Nogueira, Novel sorption-based methodologies for static microextraction analysis: A review on SBSE and related techniques, Anal Chim Acta. 757 (2012) 1-10. doi:10.1016/j.aca.2012.10.033.

[16] F. Wang, J. Zheng, J. Qiu, S. Liu, G. Chen, Y. Tong, et al., In situ hydrothermally grown TiO2@C core-shell nanowire coating for highly sensitive solid phase microextraction of polycyclic aromatic hydrocarbons, ACS Appl. Mater. Interfaces. 9 (2017) 1840-1846. doi:10.1021/acsami.6b14748.

[17] N.R. Neng, A.R. Silva, J.M. Nogueira, Adsorptive micro-extraction techniques--novel analytical tools for trace levels of polar solutes in aqueous media, J Chromatogr A. 1217 (2010) 7303-7310. 
doi:10.1016/j.chroma.2010.09.048.

644 [18] S.M. Ahmad, C. Almeida, N.R. Neng, J.M.F. Nogueira, Bar adsorptive microextraction $(\mathrm{BA} \mu \mathrm{E})$ coated with mixed sorbent phases-Enhanced selectivity for the determination of non-steroidal anti-inflammatory drugs in real matrices in combination with capillary electrophoresis., J. Chromatogr. B. Analyt. Technol. Biomed. Life Sci. 1008 (2016) 115-24. doi:10.1016/j.jchromb.2015.11.018.

[19] C. Almeida, J.M.F. Nogueira, Determination of steroid sex hormones in real matrices by bar adsorptive microextraction (BA $\mu \mathrm{E})$., Talanta. 136 (2015) 145-54. doi:10.1016/j.talanta.2014.11.013.

[20] N. Fechler, S.A. Wohlgemuth, P. Jäker, M. Antonietti, Salt and sugar: Direct synthesis of high surface area carbon materials at low temperatures via hydrothermal carbonization of glucose under hypersaline conditions, J. Mater. Chem. A. 1 (2013) 9418-9421. doi:10.1039/c3ta10674h.

[21] ChemAxon, Marvin 6.2.2, (2014). http://www.chemaxon.com.

[22] A.S. Mestre, C. Freire, J. Pires, A.P. Carvalho, M.L. Pinto, High 660 performance microspherical activated carbons for methane storage and landfill gas or biogas upgrade, J. Mater. Chem. A. 2 (2014) 15337-15344.

[23] A.S. Mestre, E. Tyszko, M.A. Andrade, M. Galhetas, C. Freire, A.P. Carvalho, Sustainable activated carbons prepared from a sucrose-derived hydrochar: Remarkable adsorbents for pharmaceutical compounds, RSC Adv. 5 (2015) 19696-19707. doi:10.1039/c4ra14495c. 
667 [24] T.A.G. Duarte, A.P. Carvalho, L.M.D.R.S. Martins, Styrene oxidation

668

669

670

671

672

673

674

675

676

677

678

679

680

681

682

683

684

685

686

687

688

689

690 catalyzed by copper(II) C-scorpionates in homogenous medium and immobilized on sucrose derived hydrochars, Catal. Today. (2019) in press. doi:10.1016/j.cattod.2019.04.044.

[25] R. Demir-Cakan, N. Baccile, M. Antonietti, M.M. Titirici, Carboxylate-rich carbonaceous materials via one-step hydrothermal carbonization of glucose in the presence of acrylic acid, Chem. Mater. 21 (2009) 484-490. doi:10.1021/cm802141h.

[26] A.S. Mestre, R.A. Pires, I. Aroso, E.M. Fernandes, M.L. Pinto, R.L. Reis, et al., Activated carbons prepared from industrial pre-treated cork: Sustainable adsorbents for pharmaceutical compounds removal, Chem. Eng. J. 253 (2014) 408-417. doi:10.1016/j.cej.2014.05.051.

[27] J. Rouquerol, P. Llewellyn, F. Rouquerol, Is the bet equation applicable to microporous adsorbents?, 2991 (2007) 49-56. doi:10.1016/S01672991(07)80008-5.

[28] M. Thommes, K. Kaneko, A. V. Neimark, J.P. Olivier, F. RodriguezReinoso, J. Rouquerol, et al., Physisorption of gases, with special reference to the evaluation of surface area and pore size distribution (IUPAC Technical Report), Pure Appl. Chem. 87 (2015) 1051-1069. doi:10.1515/pac-2014-1117.

[29] F. Rouquerol, J. Rouquerol, K.S.W.S.W.K. Sing, P. Llewellyn, G. Maurin, J. Rouquerol, et al., Adsorption by Powders and Porous Solids, 2014. doi:10.1016/B978-0-08-097035-6.00012-7.

[30] F. Rodriguez-Reinoso, J.M. Martin-Martinez, C. Prado-Burguete, B. 
McEnaney, A standard adsorption isotherm for the characterization of activated carbons, J. Phys. Chem. 91 (1987) 515-516. doi:10.1021/j100287a006.

[31] J. Jagiello, J.P. Olivier, 2D-NLDFT adsorption models for carbon slitshaped pores with surface energetical heterogeneity and geometrical corrugation, Carbon 55 (2013) 70-80. doi:10.1016/j.carbon.2012.12.011.

[32] J.S. Noh, J.A. Schwarz, Estimation of the point of zero charge of simple oxides by mass titration, J. Colloid Interface Sci. 130 (1989) 157-164. doi:10.1016/0021-9797(89)90086-6.

[33] C. Almeida, R. Strzelczyk, J.M. Nogueira, Improvements on bar adsorptive microextraction (BAmuE) technique--application for the determination of insecticide repellents in environmental water matrices, Talanta. 120 (2014) 126-134. doi:10.1016/j.talanta.2013.11.031.

[34] N.R. Neng, A.S. Mestre, A.P. Carvalho, J.M. Nogueira, Cork-based activated carbons as supported adsorbent materials for trace level analysis of ibuprofen and clofibric acid in environmental and biological matrices, J Chromatogr A. 1218 (2011) 6263-6270. doi:10.1016/j.chroma.2011.07.025.

[35] S. Comtois-Marotte, T. Chappuis, S. Vo Duy, N. Gilbert, A. Lajeunesse, S. Taktek, et al., Analysis of emerging contaminants in water and solid samples using high resolution mass spectrometry with a $Q$ Exactive orbital ion trap and estrogenic activity with YES-assay, Chemosphere. 166 (2017) 400-411. doi:10.1016/j.chemosphere.2016.09.077.

[36] V.K. Balakrishnan, K.A. Terry, J. Toito, Determination of sulfonamide 
antibiotics in wastewater: A comparison of solid phase microextraction and solid phase extraction methods, J. Chromatogr. A. 1131 (2006) 1-10. doi:10.1016/j.chroma.2006.07.011.

718

[37] F.H. Salami, M.E.C. Queiroz, Microextraction in packed sorbent for analysis of sulfonamides in poultry litter wastewater samples by liquid chromatography and spectrophotometric detection, J. Liq. Chromatogr. Relat. Technol.

37 2377-2388. doi:10.1080/10826076.2013.836710.

[38] N. Gilart, N. Miralles, R.M. Marce, F. Borrull, N. Fontanals, Novel coatings for stir bar sorptive extraction to determine pharmaceuticals and personal care products in environmental waters by liquid chromatography and tandem mass spectrometry, Anal Chim Acta. 774 (2013) 51-60. doi:10.1016/j.aca.2013.03.010.

[39] N. AL-Hadithi, B. Saad, M. Grote, A solid bar microextraction method for the liquid chromatographic determination of trace diclofenac, ibuprofen and carbamazepine in river water, Microchim. Acta. 172 (2011) 31-37. doi:10.1007/s00604-010-0463-5.

[40] S. V Duy, P.B. Fayad, B. Barbeau, M. Prevost, S. Sauve, Using a novel sol-gel stir bar sorptive extraction method for the analysis of steroid hormones in water by laser diode thermal desorption/atmospheric chemical ionization tandem mass spectrometry, Talanta. 101 (2012) 337345. doi:10.1016/j.talanta.2012.09.036.

[41] C. V Antoniou, E.E. Koukouraki, E. Diamadopoulos, Analysis of Selected Pharmaceutical Compounds and Endocrine Disruptors in Municipal 
Wastewater Using Solid-Phase Microextraction and Gas Chromatography, Water Environ. Res. 81 (2009) 664-669. doi:10.2175/106143008X390834.

[42] M.G. Pintado-Herrera, E. González-Mazo, P.A. Lara-Martín, Environmentally friendly analysis of emerging contaminants by pressurized hot water extraction-stir bar sorptive extraction-derivatization and gas chromatography-mass spectrometry, Anal. Bioanal. Chem. 405 (2013) 401-411. doi:10.1007/s00216-012-6453-1.

[43] A.R.M. Silva, F.C.M. Portugal, J.M.F. Nogueira, Advances in stir bar sorptive extraction for the determination of acidic pharmaceuticals in environmental water matrices Comparison between polyurethane and polydimethylsiloxane polymeric phases., J. Chromatogr. A. 1209 (2008) 10-6. doi:10.1016/j.chroma.2008.08.103.

[44] A. Giordano, J. Vásquez, M. Retamal, L. Ascar, Ibuprofen, carbamazepine and $\beta$-estradiol determination using thin-film microextraction and gas chromatography-mass spectrometry, J. Braz. Chem. Soc. 27 (2016) 1744-1749. doi:10.5935/0103-5053.20160055.

[45] A.R.M. Silva, F.C.M. Portugal, J.M.F. Nogueira, Advances in stir bar sorptive extraction for the determination of acidic pharmaceuticals in environmental water matrices Comparison between polyurethane and polydimethylsiloxane polymeric phases, J. Chromatogr. A. 1209 (2008) 10-16. doi:10.1016/j.chroma.2008.08.103.

[46] M.G. Pintado-Herrera, E. González-Mazo, P.A. Lara-Martín, Environmentally friendly analysis of emerging contaminants by 
pressurized hot water extraction-stir bar sorptive extraction-derivatization and gas chromatography-mass spectrometry, Anal. Bioanal. Chem. 405 (2013) 401-411. doi:10.1007/s00216-012-6453-1.

766 [47] S.M. Ahmad, C. Almeida, N.R. Neng, J.M.F. Nogueira, Application of bar adsorptive microextraction $(\mathrm{BA} \mu \mathrm{E})$ for anti-doping control screening of anabolic steroids in urine matrices, J Chromatogr B Anal. Technol Biomed Life Sci. 969C (2014) 35-41. doi:10.1016/j.jchromb.2014.07.040.

770

771

772 